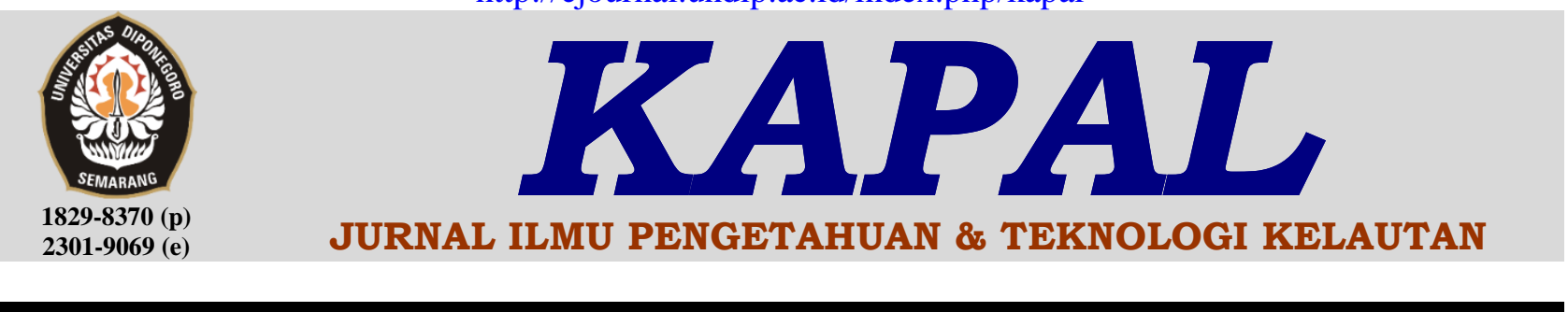

\title{
Identifikasi Kegagalan Moving Bridge System Dermaga Penyeberangan Roro Air Putih Kabupaten Bengkalis
}

\author{
Edy Haryanto $^{l *)}$ \\ 1) Jurusan Teknik Perkapalan, Politeknik Negeri Bengkalis \\ Jl. Bathin Alam, Bengkalis, Indonesia
}

\begin{abstract}
Abstrak
Dermaga penyeberangan roro di Pelabuhan Air Putih Bengkalis mengalami kerusakan pada sistem hidroliknya, sehingga Moving Bridge (MB) yang berfungsi untuk mengatur ketinggian dermaga dengan car deck kapal tidak berfungsi. Jika ketinggian dermaga dan ketinggian car decknya sangat jauh, maka akan menyulitkan proses masuk keluarnya kendaraan sehingga bisa menubruk atau sangkut, sehingga bisa membuat kendaraan tersebut rusak dan bisa membahayakan keselamatan. Berdasarkan situasi yang ada, root cause analysis berguna untuk mencari akar permasalahan sehingga kerugian dapat diminimalkan. Dengan menggunakan metode Fault Tree Analysis dapat diketahui penyebab kerusakan sistem. Dari hasil penelitian diketahui bahwa terdapat 14 bentuk kegagalan fungsi peralatan hidrolik di demaga. Komponen yang paling kritis adalah kegagalan pada konduktor berupa pipa / selang dan strainer. Untuk mengantisipasi kegagalan maka diperlukan kegiatan perawatan pencegahan seperti jadwal perawatan berkala, pengecekan sistem sebelum operasi, melindungi komponen dari pengaruh luar, pelumasan dan menjaga kebersihan.
\end{abstract}

Kata kunci : Sistem Hidrolik, Fault Tree Analysis, Komponen Kritis.

\section{PENDAHULUAN}

Adanya aktifitas pelabuhan yang cukup ramai dan Seiring dengan bertambahnya waktu, pengaruh kondisi dan lingkungan, pelabuhan penyeberangan Bengkalis - Sungai selari mengalami kerusakan pada sistem hidroliknya. Sehingga, Moving Bridge (MB) yang dirancang dengan menggunakan sistem hidrolik yang berada dipelabuhan tersebut tidak berjalan sesuai dengan fungsinya. Hal ini tentu saja dapat merugikan semua pengguna jasa kapal terutama kendaraan roda 4 bertype sedan dan Minibus yang bisa menabrak dan sangkut saat memasuki kapal. Masalah ini juga dapat menimbulkan bahaya bagi keselamatan pengguna jasa transportasi laut dan menimbulkan kerugian yang besar jika tidak dibenahi dari sekarang. Untuk mengatasi masalah ini akan di analisa semua kemungkinan kerusakan yang terdapat pada sistem hidrolik yang berada didermaga tersebut menggunakan metode Fault tree Analysis untuk mencari dan menemukan gangguan atau kerusakan (fault tracing) pada bagian-bagian yang tidak berfungsi dari sistem hidrolik.

\subsection{Latar Belakang}

Dermaga penyeberangan ferry di pelabuhan Bengkalis merupakan salah satu dermaga utama yang bisa menunjang kegiatan serta meningkatkan ekonomi masyarakat sekitar. Letaknya di Desa Air Putih Kabupaten Bengkalis. Pelabuhan ini dirancang agar dapat menghubung kan ibukota Kabupaten Bengkalis di pulau Bengkalis dengan Sungai Pakning, sehingga dapat menghubungkan Pulau Bengkalis dengan kota-kota di daratan pulau Sumatera.

Dermaga mengalami kerusakan pada sistem hidroliknya yang mana fungsi sistem hidrolik ini sangat berguna untuk menyesuaikan ketinggian dermaga dengan car deck kapal. Jika ketinggian pelabuhan dan ketinggian car deck nya sangat jauh, maka akan menyulitkan proses masuk - keluarnya kendaraan dan bisa menubruk atau sangkut pada bagian ujung ramp door, sehingga bisa membuat kendaraan tersebut rusak dan bisa membahayakan keselamatan.

Untuk itu dilakukan penelitian dan analisa penyebab terbesar kerusakan pada komponen komponen hidrolik moving bridge di dermaga 
penyeberangan Bengkalis - Sei. Selari Kabupaten Bengkalis tentang kerusakan yang terjadi pada sistem hidroliknya.

\subsection{Perumusan Masalah}

Dari latar belakang masalah yang telah dikemukakan, maka dapat diidentifikasi beberapa hal yaitu:

1. Bagaimana untuk mengidentifikasi kerusakan pada sistem hidrolik.

2. Perawatan apa saja yang dapat diberikan dalam mengantisipasi terjadinya kegagalan.

\subsection{Batasan Masalah}

Untuk merealisasikan pengerjaan Penelitian ini, diperlukan batasan - batasan masalah. yakni:

1. Analisa teknis digunakan untuk Moving Bridge (MB) di dermaga penyeberangan desa Air Putih, Kabupaten Bengkalis.

2. Kerusakan peralatan atau komponen yang terjadi bisa disebabkan oleh human error

3. Analisa teknis tidak membahas diluar sistem ini.

\subsection{Tujuan}

Adapun tujuan dari Penelitianini adalah:

1. Mencari penyebab kerusakan sistem hidrolik di Dermaga Penyeberangan Bengkalis - Sei. Pakning yang digunakan untuk MB (Moving Bridge).

2. Mengetahui komponen Hidrolik yang paling berpotensi besar menimbulkan kerusakan.

3. Menentukan strategi yang tepat untuk mengatasi resiko yang paling dominan terhadap sistem hidrolik dipelabuhan.

\subsection{Manfaat}

Manfaat yang dapat diperoleh dari penulisan Penelitianini adalah :

1. Ketepatan suatu metode dalam mengidentifikasi kerusakan sistem komponen.

2. Dapat dijadikan acuan dalam menganalisa suatu peralatan yang rusak.

\section{METODE}

Metode yang akan digunakan dalam penelitian ini meliputi:

1. Observasi lapangan

2. Identifikasi masalah

3. Studi pustaka

5. Observasi lapangan lebih lanjut

6. Mengambil data yang diperlukan

7. Mengolah data

8. Menyusun solusi masalah

9. Menarik kesimpulan

\subsection{Urutan Pelaksanaan Pengerjaan}

Uraian metode yang digunakan dalam Penelitian ini secara garis besar adalah menggunakan metode pengumpulan data dan menganalisa data tersebut dengan menggunakan metode Fault Tree Analysis untuk dapat menghasilkan kesimpulan dari hasil pekerjaan. Tahapan-tahapan dalam melakukan analisa adalah sebagai berikut :

1. Identifikasi masalah

Pada langkah ini dilakukan peninjauan awal untuk mengidentifikasi permasalahan yang terjadi, yakni kegagalan pada komponen yang meng ganggu jalannya proses. Identifikasi kondisi awal tersebut akan digunakan untuk merumuskan permasalahan dengan jelas dan menetapkan tujuan penelitian, serta penentuan batasan batasan penelitian dan asumsi yang digunakan.

2. Jenis dan sumber data

Jenis data yang digunakan dalam penelitian ini nanti bersumber dari :

1. Dari pengamatan dan wawancara langsung dari pihak terkait dilapangan. Baik keterangan secara tertulis maupun lisan yang berhubungan dengan aktifitas didermaga penyeberangan pelabuhan Bengkalis.

2. Studi literature untuk mendapatkan dan mempelajari referensi yang digunakan dalam menganalisa suatu masalah penelitian yaitu untuk menyusun konsep dasar bagaimana mengetahui persentase terbesar kerusakan pada sistem hidrolik. Studi literature dapat diperoleh dari dokumen resmi yang dianggap relevan seperti buku-buku, artikel dari media cetak maupun dari internet atau jurnal online.

3. Data spesifikasi peralatan sistem hidrolik.

Data-data spesifikasi peralatan yang digunakan untuk mendapatkan penyebab kerusakan pada sistem hidrolis didermaga penyeberangan dipelabuhan Bengkalis. Data-data tersebut adalah sebagai berikut :

1. Tangki (reservoir) sebagai tempat penyimpanan fluida.

2. Motor Hidrolik

3. Pompa Hidrolik.

4. Pipa dan selang sebagai tempat mengalirnya fluida.

5. Katup (Valve).

6. Aktuator 
Sedangkan yang berfungsi sebagai komponen pelayanan dan pelengkap pada sistem hidrolik adalah sebagai berikut :
1. Filter
2. Cooler
3. Thermometer
4. Penunjuk tekanan
5. Fluida hidrolis
6. Reservoir
7. Indicator level pengisian
8. Indicator tekanan
9. Pangatur sirkuit aliran

4. Data pendukung

Adapun data-data tersebut adalah sebagai berikut :

1. Dimensi dermaga

2. Gambar denah dermaga

3. Gambar konstruksi dermaga

4. Data pasang surut diarea dermaga

5. Data operasi penggunaan dermaga dalam sehari dan dirangkum dalam tahun

6. Data penumpang, barang dan kendaraan dalam tahun

7. Kondisi dermaga

\subsection{Pengolahan data}

Tujuan Pengolahan data dilakukan untuk mendapatkan hasil dari analisa dengan menggunakan metode Fault Tree yang merupakan suatu studi dengan pendekatan deduktif, yang memfokuskan pada kejadian yang tidak dikehendaki (accidents, main system failures, etc), kemudian dicari penyebab-penyabab dari kejadian tersebut.

\subsection{Analisa kualitatif}

Evaluasi sistem secara kuantitatif dilakukan dengan memodelkan sistem hidrolik kedalam reliability blok diagram. Reliability blok diagram tersebut merupakan gambaran secara grafis tentang hubungan komponen - komponen yang ada didalam sistem hidrolik. Rangkaian dasar yang sering digunakan dalam rangkaian reliability blok diagram yaitu susunan seri, parallel dan stand-by.

\subsection{Analisa teknis dan perbaikan}

Adapun analisa teknis yang dilakukan adalah menganalisa penyebab kerusakan pada sistem hidrolik dengan menggunakan metode fault tree yang mana penganalisaannya menggunakan evaluasi kualitatif dari sebuah fault tree yang dapat dilakukan berdasarkan minimal cut set.
Tahapan akhir pada penelitian ini adalah menyimpulkan hasil penelitian yang berusaha menjawab tujuan dari penelitian yang dilakukan.

\section{HASIL DAN PEMBAHASAN}

Pada bab ini akan dibahas mengenai pengumpulan data yang diperoleh dengan melakukan interview langsung kepada pihak Dinas Perhubungan Laut (HUBLA) Kabupaten Bengkalis.

\subsection{Sistem Hidrolik}

1. Acumulator / Motor penggerak

2. Pompa

3. Reservoir.

4. Konduktor
a. Selang Hidrolik
b.Pipa Hidrolik
c. Katup (Valve)

5. Piston Hidrolik

6. Tiang Penyangga Beban

7. Lubang Penahan Beban

8. Dermaga Pelabuhan penyeberangan desa Air Putih Bengkalis

\subsection{Kondisi Dermaga}

1. Lokasi dermaga penyeberangan dipelabuhan Bengkalis

Lokasi Dermaga penyeberangan Pelabuhan Bengkalis bisa dilihat pada gambar di bawah ini :

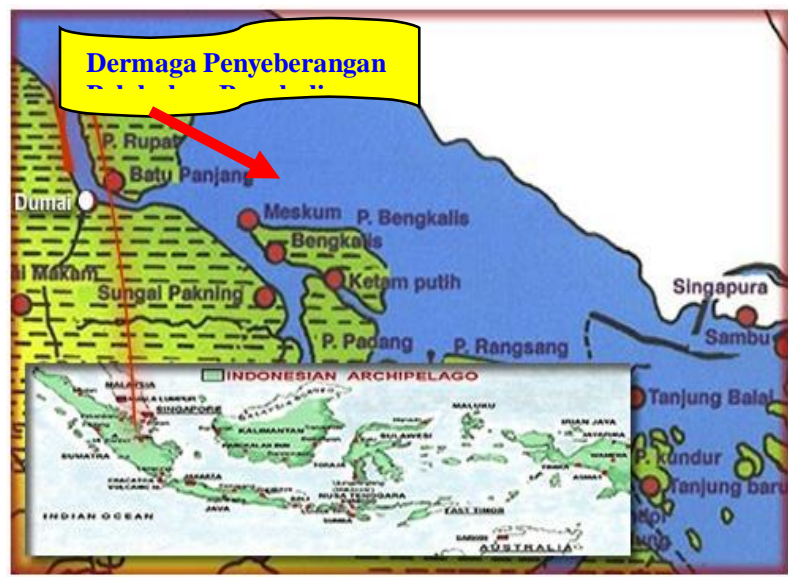

Gambar 3.1 Lokasi dermaga penyeberangan pelabuhan Bengkalis

\subsection{Kesimpulan dan saran}




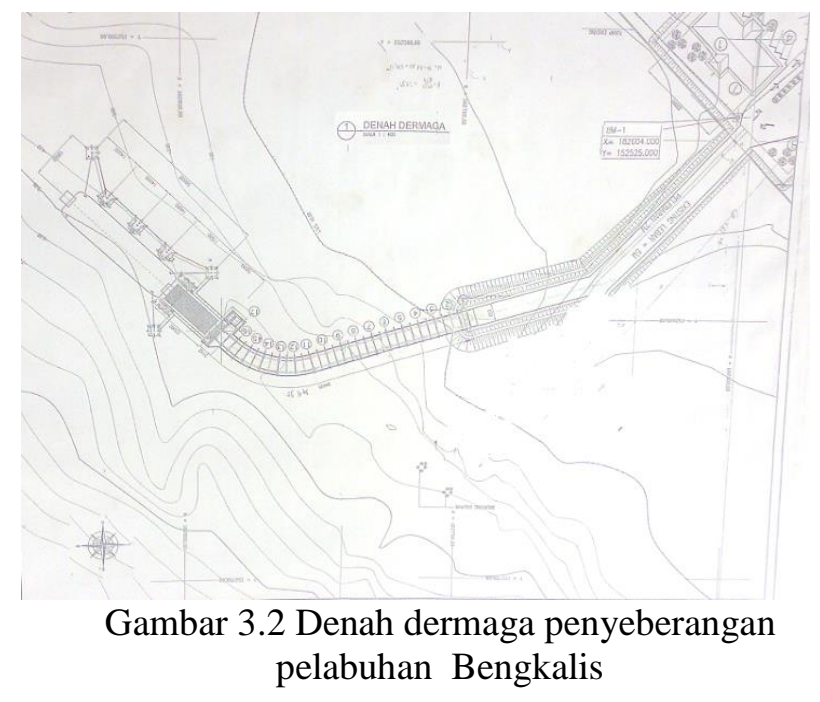

\section{Kondisi perairan}

Perairan disekitar pelabuhan mempunyai peran yang penting sebagai pintu gerbang perekonomian nasional Indonesia khususnya Kabupaten Bengkalis dan Kabupaten lainnya di sekitarnya. Kondisi pasang surut tertinggi $\pm 536 \mathrm{~cm}$ dan terendah $\pm 42 \mathrm{~cm}$. Dengan mengetahui kondisi perairan ini bisa mengetahui kapan terjadinya pasang surut yang terbesar dan pasang surut yang terkecil, untuk mengetahui penggunaan sistem hidrolik dengan menurunkan atau menaikkan dermaga sehingga berguna untuk membantu analisa.

3. Data pertumbuhan pengguna dermaga penyeberangan pertahun

Dari Tahun 2009 sampai dengan Oktober 2016 jumlah arus penumpang Dermaga Ferry Penyeberangan baik keberangkatan dari bengkalis maupun kedatangan dari sungai pakning menunjukkan peningkatan yang besar. Data arus kendaraan yang keluar masuk di dermaga Penyeberangan Air Putih Bengkalis selama 6 tahun terakhidapat di lihat pada gambar 3.3 dibawah ini:

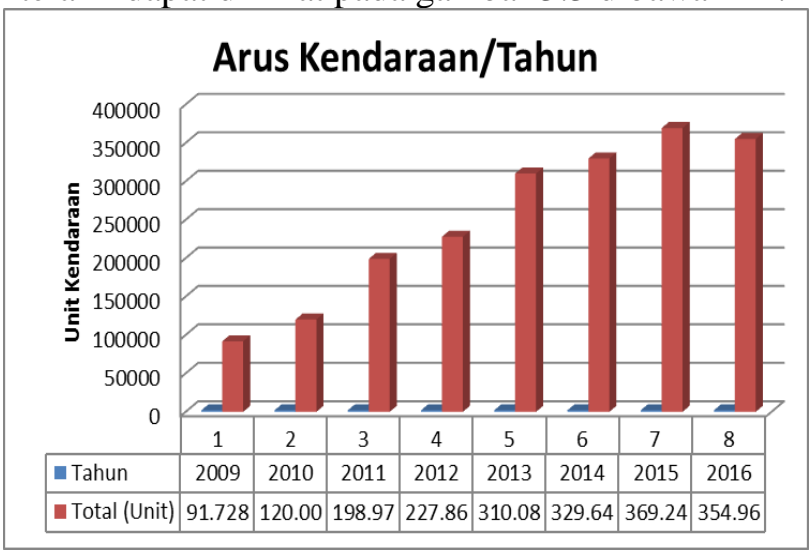

Gambar 3.3 Data Arus Kendaraan

Sumber PT. ASDP Penyeberangan Air Putih

\section{Jadwal Operasi}

Tabel 3.1 Jadwal Keberangkatan Kapal
Jadwal Kapal ro-ro Penyeberangan Air Putih (Bengkalis) - Sungai Selari (Sungai Pakning) * berangkat tiap har :

\begin{tabular}{|c|c|c|c|c|c|}
\hline \multirow[b]{2}{*}{ Trip- } & \multicolumn{2}{|c|}{ Senin s/d Kamis } & \multicolumn{2}{|c|}{ Jumat s/d Minggu } & \multirow{2}{*}{$\begin{array}{c}\text { Kapal Yang } \\
\text { beroperasi }\end{array}$} \\
\hline & $\begin{array}{c}\text { Air Putih } \\
\text { (jam) }\end{array}$ & $\begin{array}{c}\text { Sei. Selari } \\
\text { Pakning } \\
\text { (jam) }\end{array}$ & $\underset{(\text { jam })}{\text { Air Putih }}$ & $\begin{array}{c}\text { Sei. Selari } \\
\text { Pakning } \\
\text { (jam) }\end{array}$ & \\
\hline 1 & $07.00 \mathrm{WIB}$ & $06.30 \mathrm{WIB}$ & $07.00 \mathrm{WIB}$ & $07.00 \mathrm{WIB}$ & KMP. Aingmas I \\
\hline 2 & $08.00 \mathrm{WIB}$ & $07.30 \mathrm{WIB}$ & 07.45 WIB & $07.45 \mathrm{WIB}$ & KMP. Banyumas I \\
\hline 3 & $09.00 \mathrm{WIB}$ & $08.30 \mathrm{WIB}$ & $08.30 \mathrm{WIB}$ & $08.30 \mathrm{WIB}$ & KMP. Swarna Putri \\
\hline 4 & $10.00 \mathrm{WIB}$ & $09.30 \mathrm{WIB}$ & $09.15 \mathrm{WIB}$ & $09.15 \mathrm{WIB}$ & KMP. Bahari Nusantara \\
\hline 5 & $11.00 \mathrm{WIB}$ & $10.30 \mathrm{WIB}$ & $10.00 \mathrm{WIB}$ & $10.00 \mathrm{WIB}$ & KMP. Aingmas I \\
\hline 6 & $12.00 \mathrm{WIB}$ & $11.30 \mathrm{WIB}$ & 10.45 WIB & 10.45 WIB & KMP. Banyumas I \\
\hline 7 & $13.00 \mathrm{WIB}$ & $12.30 \mathrm{WIB}$ & $11.30 \mathrm{WIB}$ & $11.30 \mathrm{WIB}$ & KMP. Swarna Putri \\
\hline 8 & $14.00 \mathrm{WIB}$ & $13.30 \mathrm{WIB}$ & $12.15 \mathrm{WIB}$ & $12.15 \mathrm{WIB}$ & KMP. Bahari Nusantara \\
\hline 9 & $15.00 \mathrm{WIB}$ & $14.30 \mathrm{WIB}$ & $13.00 \mathrm{WIB}$ & $13.00 \mathrm{WIB}$ & KMP. Aingmas I \\
\hline 10 & $16.00 \mathrm{WIB}$ & $15.30 \mathrm{WIB}$ & 13.45 WIB & $13.45 \mathrm{WIB}$ & KMP. Banyumas I \\
\hline 11 & $17.00 \mathrm{WIB}$ & $16.30 \mathrm{WIB}$ & $14.30 \mathrm{WIB}$ & $14.30 \mathrm{WIB}$ & KMP. Swarna Putri \\
\hline 12 & $18.00 \mathrm{WIB}$ & $17.30 \mathrm{WIB}$ & 15.15 WIB & $15.15 \mathrm{WIB}$ & KMP. Bahari Nusantara \\
\hline 13 & $19.00 \mathrm{WIB}$ & $18.30 \mathrm{WIB}$ & $16.00 \mathrm{WIB}$ & $16.00 \mathrm{WIB}$ & KMP. Aingmas I \\
\hline 14 & $20.00 \mathrm{WIB}$ & $19.30 \mathrm{WIB}$ & $16.45 \mathrm{WIB}$ & $16.45 \mathrm{WIB}$ & KMP. Banyumas I \\
\hline 15 & $21.00 \mathrm{WIB}$ & $20.30 \mathrm{WIB}$ & $17.30 \mathrm{WIB}$ & $17.30 \mathrm{WIB}$ & KMP. Swarna Putri \\
\hline 16 & $22.00 \mathrm{WIB}$ & $21.30 \mathrm{WIB}$ & 18.15 WIB & 18.15 WIB & KMP. Bahari Nusantara \\
\hline 17 & $23.00 \mathrm{WIB}$ & $22.30 \mathrm{WIB}$ & $19.00 \mathrm{WIB}$ & $19.00 \mathrm{WIB}$ & KMP. Aingmas I \\
\hline 18 & - & - & $19.45 \mathrm{WIB}$ & 19.45 WIB & KMP. Banyumas I \\
\hline 19 & - & - & $20.30 \mathrm{WIB}$ & $20.30 \mathrm{WIB}$ & KMP. Swarna Putri \\
\hline 20 & - & - & $21.30 \mathrm{WIB}$ & $21.30 \mathrm{WIB}$ & KMP. Bahari Nusantara \\
\hline 21 & - & - & $23.00 \mathrm{WIB}$ & $23.00 \mathrm{WIB}$ & KMP. Aingmas I \\
\hline
\end{tabular}

Sumber: Dinas Perhubungan Kabupaten Bengkalis

Jumlah trip perhari dirangkum menjadi jumlah trip pertahun Pertumbuhan dengan menggabungkan operasi kapal sebelumnya dengan jumlah trip kapal dari tahun 2009 sampai dengan oktober 2016.

Tabel 3.2 jumlah trip kapal yang singgah dan berlabuh di pelabuhan penyeberangan Air Putih Bengkalis

\begin{tabular}{ccc} 
Tahun & $\begin{array}{c}\text { Jumlah trip } \\
\text { total pertahun }\end{array}$ & $\begin{array}{c}\text { Pertumbuhan } \\
(\%)\end{array}$ \\
$\mathbf{2 0 0 9}$ & 2140 & 0.33 \\
$\mathbf{2 0 1 0}$ & 2860 & 1.34 \\
$\mathbf{2 0 1 1}$ & 4310 & 1.51 \\
$\mathbf{2 0 1 2}$ & 4310 & 1.00 \\
$\mathbf{2 0 1 3}$ & 5740 & 1.33 \\
$\mathbf{2 0 1 4}$ & 6110 & 1.06 \\
$\mathbf{2 0 1 5}$ & 6110 & 1.00 \\
$\mathbf{2 0 1 6}$ & 6110 & 1.00 \\
\hline
\end{tabular}

Sumber PT. ASDP Penyeberangan Air Putih

\subsection{Analisa Kerusakan Sistem Hidrolik dengan menggunakan Metode Fault Tree Analysis (FTA)}

Pada Penelitianini akan di analisa sejauh mana pengaruh prosedur dan proses kerja suatu komponen hidrolik sehingga terjadi kerusakan dalam pengoperasiannya.

Untuk menganalisa kerusakan pada sistem hidrolik ini, digunakan metode Fault Tree Analysis (FTA). Dimana penganalisaan berdasarkan data data kerja yang ada. Berikut gambar sirkuit sistem hidrolik pada dermaga penyeberangan desa Air Putih Bengkalis. 


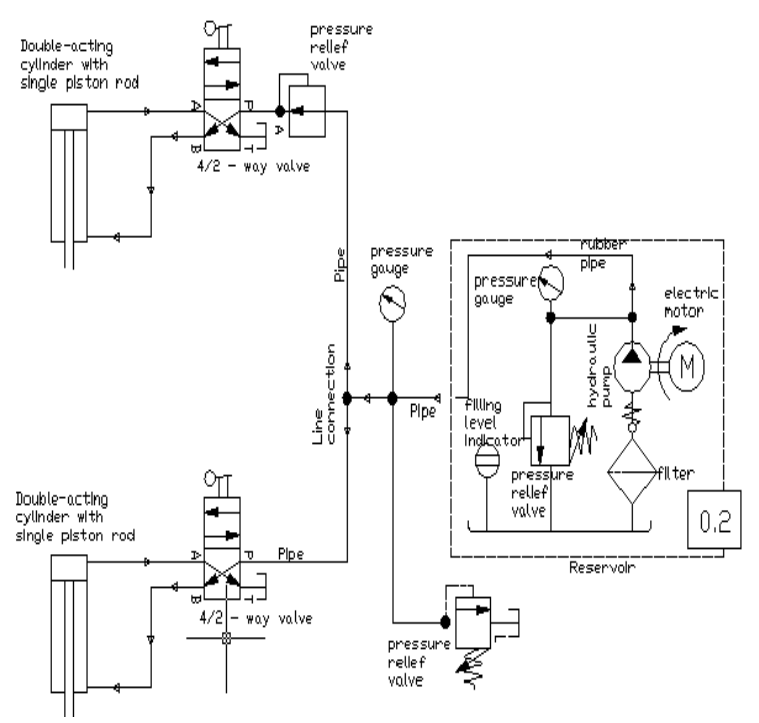

Gambar 3.4. Diagram Sistem Hidrolik Di

Dermaga Penyeberangan Pelabuhan Bengkalis Fungsi:

a. Tangki minyak (Reservoir)

Berfungsi sebagai tandon/penyimpanan cairan hidrolik (fluida).

b. Strainer

Berfungsi untuk menyaring cairan hidrolik agar terpisah dari kotoran.

c. Motor listrik

Sebagai penyuplai daya yang digunakan untuk memutar pompa.

d. Pompa.

Alat yang berfungsi untuk mengalirkan cairan hidrolik dengan memompa cairan dari tangki minyak (Reservoir) ke sistem untuk menggerakkan aktuator.

e. Pressure gauge

Katup yang berfungsi untuk mengetahui tekanan sistem.

f. Filter

digunakan untuk menyaring cairan hidrolika dari sistem sebelum masuk ke tangki.

g. Reducting valve

untuk memperkecil tekanan pada piston.

h. Konduktor

Penghubung berupa selang atau pipa yang menghubungkan satu komponen dengan komponen lain sehingga terwujud satu rangkaian hidrolik,

i. Conector

Alat pengikat atau penjepit (fitting) untuk mengikatkan /menyambungkan konduktor pada komponen.

j. Silinder (Aktuator)

Alat ini berfungsi untuk melakukan gerakan naik dan turun dari suatu sistem hidrolik

\subsection{Klasifikasi kerusakan sistem hidrolik}

1. Klasifikasi yang disebabkan oleh factor manusia sebagai berikut : a. Kurang pengetahuan

b. Ceroboh

c. Kurang pemeliharaan dan perawatan

d. Peralatan yang kurang lengkap

e. Bekerja dengan mesin yang bukan haknya, melupakan tanda keamanan atau peringatan.

f. Bekerja dengan kecepatan yang berbahaya (terlalu lambat, terlalu cepat dan tergesa - gesa).

g. Tidak memasang, menyetel alat pengaman mesin.

h. Mempergunakan alat yang tidak aman.

i. Bekerja pada beban yang menggantung.

j. Tidak memperhatikan peraturan, bercanda, emosi dan lain - lain sewaktu menjalankan sistem.

2. Keadaan lingkungan yang tidak aman (Unsafe Condition)

3. Material

a. Terdapat partikel - pertikel kecil pada permukaan material yang sedang beroperasi.

b. Material yang kurang sempurna (cacat dari pabrik)

c. Menggunakan material yang tidak mengikuti standar yang telah ditetapkan.

d. Umur material yang udah tua

e. Karatan.

f. Salah dalam perencanaan/design awal sehingga menimbulkan Tekanan kerja yang berlebihan.

\subsection{Reliability blok diagram}

Reliability blok diagram merupakan gambaran secara grafis tentang hubungan komponen - komponen yang ada di dalam sistem. Sistem hidrolik dapat dimodelkan kedalam blok diagram keandalan dengan susunan seri. Karena komponen - komponen ini harus bekerja atau berfungsi seluruhnya. Blok diagram keandalan sistem hidrolik dapat dilihat pada gambar 3.5.

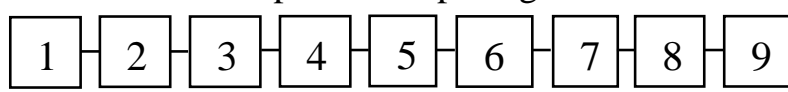

Gambar 3.5. Blok Diagram Keandalan Sistem Hidrolik

Nama komponen pada blok diagram keandalan tersebut yaitu:

1 : Motor listrik

2 : Pompa hidrolik

3 : Tangki minyak hidrolik (Reservoir)

4 : Strainer/Filter

5 : Indikator level pengisian

6 : Pressure relief valve 
7 : Selang hidrolik

8 : Pipa hidrolik

9 : Aktuator (piston)

\subsection{Pemilihan komponen kritis}

Pemilihan komponen kritis dengan menggunakan analisa kualitatif FTA dapat dilihat pada gambar 3.6 berikut.

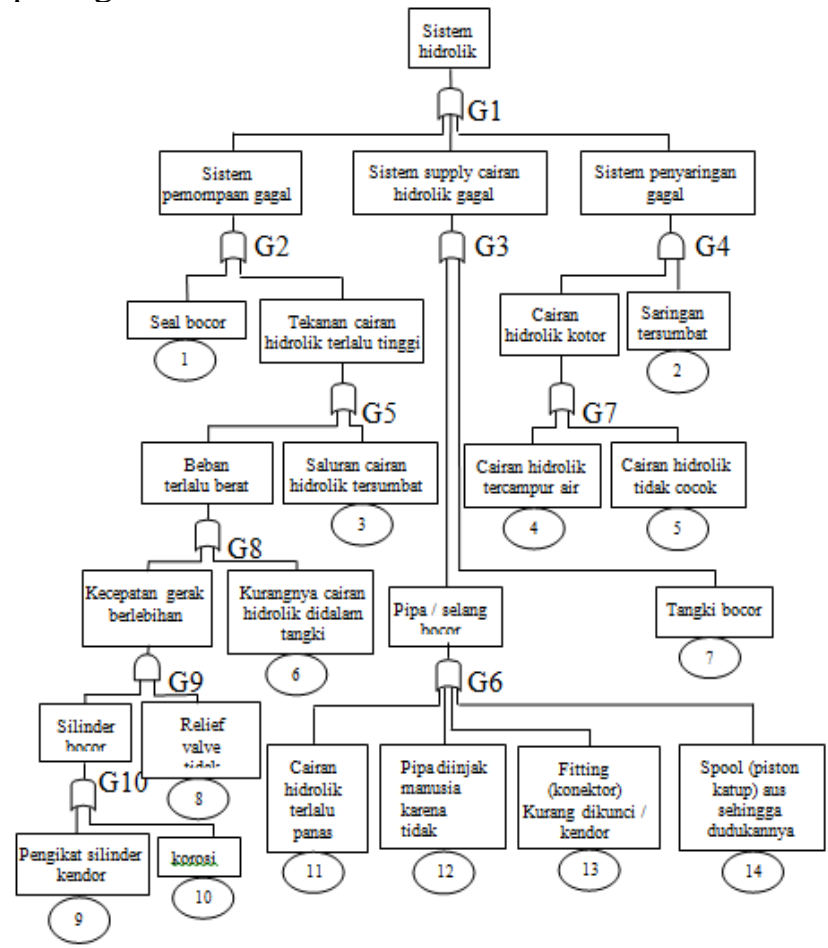

Gambar 3.6. Blok Diagram Keandalan Sistem Hidrolik

Sumber: Data Olahan

Dari fault tree diatas, dapat diketahui komponenkomponen atau penyebab-penyebab terjadinya kegagalan sistem dengan mencari minimal cut set yang dapat ditentukan dengan menggunakan metode MOCUS (Method Obtain Cut Set). Tabel 3.3. berikut memberi informasi minimal cut set.

Tabel 3.3. Algoritma MOCUS FTA

\begin{tabular}{cccccccc} 
Step & $\mathbf{1}$ & $\mathbf{2}$ & $\mathbf{3}$ & $\mathbf{4}$ & $\mathbf{5}$ & $\mathbf{6}$ & Cut set \\
\hline G1 & G2 & 1 & & & & & 1 \\
& & G5 & 3 & & & & 1 \\
& & & G8 & 6 & & & 1 \\
& & & & G9 & $8, \mathrm{G} 10$ & 9 & 2 \\
& & & & & & 10 & 1 \\
& G3 & 7 & & & & & 1 \\
& G6 & 11 & & & & 1 \\
& & 12 & & & & 1 \\
& & 13 & & & & 1 \\
& & 14 & & & & 1 \\
& G4 & $2, G 7$ & 4 & & & & 2 \\
& & 5 & & & & 1 \\
\hline
\end{tabular}

Sumber: Data Olahan

Semua event yang diperoleh dengan algoritma MOCUS diatas didapatkan sebanyak 14 basic event yang akan dikelompokkan menjadi enam komponen utama penyebab terjadinya kegagalan pada sistem hidrolik didermaga yakni disebabkan oleh kebocoran, kurangnya cairan hidrolik dan juga akibat tersumbat pada komponenkomponen tertentu seperti pompa, tangki, strainer, konduktor (pipa \& selang), valve dan juga actuator (piston hidrolik).

Besarnya prosentase kegagalan / kerusakan dari masing - masing komponen dapat dilihat pada gambar 4.7 berikut:

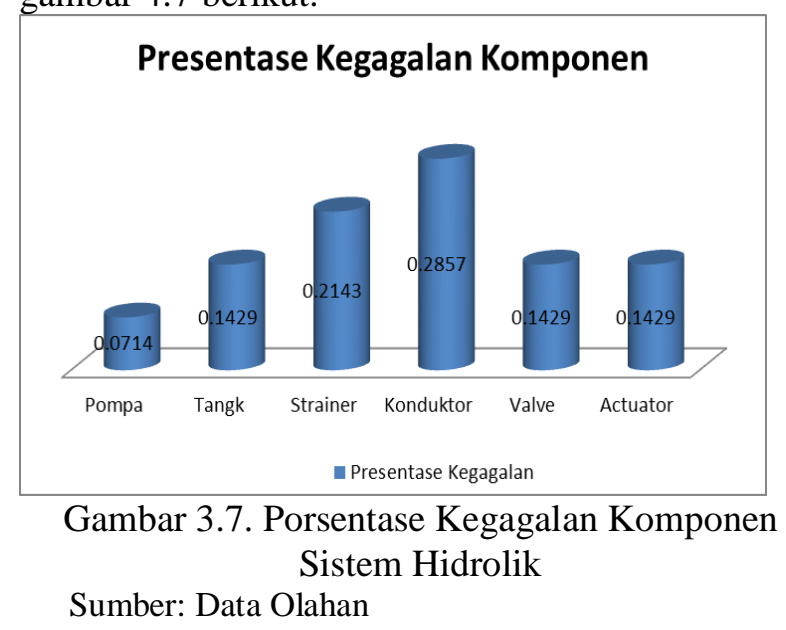

Berdasarkan grafik diatas, presentase kegagalan sistem terdapat pada komponen kunduktornya yakni sebesar $28,57 \%$. , penyebab yang kedua adalah pada strainer sebesar $21.43 \%$, sedangkan yang terkecil adalah pada komponen pompa sebesar $7.14 \%$.

\subsection{Perbaikan}

Sistem hidrolik baru 2 kali mengalami kerusakan. Selama operasi tahun 2005 hingga tahun 2016, perbaikannya memerlukan pembetulan komponen dengan waktu kerja yang lebih lama. Atau dengan penggantian komponen (replacement) dan tidak memerlukan waktu dan biaya tinggi.

\section{KESIMPULAN DAN SARAN 5.1 Kesimpulan}

Berdasarkan hasil pengolahan serta analisa data yang telah dilakukan, diperoleh kesimpulan sebagai berikut :

1. Analisa menunjukkan bahwa terdapat 14 bentuk kegagalan yang memiliki potensi terjadinya functional failures pada sistem hidrolik di dermaga.

2. Hasil penilaian resiko yang diberikan dalam FTA menunjukkan bahwa komponen kritis yang perlu mendapatkan prioritas utama/ memiliki tingkat kepentingan tinggi untuk diperhatikan adalah kegagalan pada konduktor berupa pipa / selang dan strainer.

3. Kegiatan perbaikan sistem hidrolik harus mengikuti sistematika perbaikan secara umum. 


\subsection{Saran}

Dari hasil analisa dan pembahasan yang telah dilakukan, dapat di sarankan beberapa pemikiran, seperti :

1. Komponen-komponen yang letaknya dilapangan diberi perlindungan agar tidak mudah terkena pengaruh akibat faktor manusia dan faktor lingkungan.

2. Operator harus membuat schedule perawatan dan perbaikan agar lajunya kegagalan dapat dikurangi.

3. Pekerja yang bertanggung jawab terhadap tindakan perawatan harus lebih teliti dan detail dalam menjalankan proposed task yang telah direncanakan.

\section{DAFTAR PUSTAKA}

1. Anggrahini, "Hidrolika Saluran Terbuka", CV. Citra Media, Surabaya

2. Ansell, J.J (1994) "The Reliability, Availibility and Productivieness of Systems", Chapman \& Hall Inc.

3. Billnton, R. and Ronald N Allan (1992) "Reliability Evaluation of Engineering Systems: Concepts and Techiniques, $2^{\text {nd }}$ edition", Plenum Press, New York and London.

4. Ir. Dwi Priyanta, MSE. Modul Ajar "Keandalan dan Perawatan". Jurusan Teknik Sistem Perkapalan, FTK, ITS. 2000

5. Junaedi. Ardianto, D dan Tua, S.M. (2011). "Identifikasi Kerusakan Barel Lifting Device dan Barrel Double Lit Hotcell 001/102 Di IRM. Pusat Jurnal Teknologi Bahan Bakar Nuklir Batan. ISSN 1979-2409. No 08/Tahun IV 2011.

6. N, Rudenko. 1996. Mesin Pengangkat. Diterjemahkan oleh Ir. Nazar Foead. Airlangga, Ciracas-Jakarta: IKAPI

7. Soedjono Kramadibrata. Perencanaan Pelabuhan. Ganeca Exact Bandung

8. Triatmodjo, B. 1996, Pelabuhan, Beta Offset, Yogyakarta

9. Yoki Tri Atmojo 2014. "Troubleshooting Kerusakan Sistem Hidrolik Operasi Swing Pada Excavator Hitachi Model EX 2500-6" UGM, Yogyakarta

10.webadmin@bengkalis.go.id 